\title{
Protein Drug-Loaded Polymeric Nanoparticles
}

\author{
Prasamsha Panta1, Da Yeon Kim¹, Jin Seon Kwon'1, A Reum Son'1, Kang Woo Lee², \\ Moon Suk Kim ${ }^{*}$ \\ ${ }^{1}$ Department of Molecular Science and Technology, Ajou University, Suwon, Korea \\ ${ }^{2}$ Evaluation Management Department, Korea Evaluation Institute of Industrial Technology, Seoul, Korea \\ Email: ${ }^{*}$ moonskim@ajou.ac.kr
}

Received 7 June 2014; revised 23 July 2014; accepted 5 August 2014

Copyright (C) 2014 by authors and Scientific Research Publishing Inc.

This work is licensed under the Creative Commons Attribution International License (CC BY). http://creativecommons.org/licenses/by/4.0/

c. (i) Open Access

\begin{abstract}
Considerable interest and research have focused on the administration of therapeutic proteins. For delivery of therapeutic proteins, bioavailability and stabilization of protein drugs to maintain therapeutically acceptable levels is an important challenge in clinical trials. To overcome these challenges, polymeric nanoparticles have become one of the best methods for protein delivery. In this review, we summarize the current available polymeric nanoparticles designed for protein delivery, current status, and advantages of protein delivery systems.
\end{abstract}

\section{Keywords}

Polymeric Nanoparticles, Proteins, Drug Delivery

\section{Introduction}

Proteins are large biological molecules consisting of one or more polypeptide chains [1], which perform a vast array of functions within living organisms including catalyzing metabolic reactions, replicating DNA, responding to stimuli, and transporting molecules. Proteins are highly promising drugs as theoretically only a low dose would be necessary due to the relatively specific mode of action [1]. However, proteins are susceptible to proteolysis and denaturation during in vivo administration and thus have poor bioavailability, requiring repeated administration and thus increasing patient inconvenience [2]. Considerable efforts have been devoted to improving in vivo protein stability to range from weeks instead of just days [3].

Due to rapid degradation by proteolytic enzymes and low passage through biological barriers, proteins cannot be readily delivered orally or dermally [2] [4]. Some proteins present in serum, such as opsonin, cause resistance

\footnotetext{
"Corresponding author.
} 
to functional therapeutic drug delivery systems [5] [6].

To improve bioavailability of protein drugs, methods such as hydrogels, micro- and nano-capsules, and micro-and nano-particles have been developed [4]-[7]. Among the developed methods, polymeric nanoparticles have recently been shown to improve protein stability through entrapment of proteins in nanoparticles [8]-[10]. The most important characteristic of polymeric nanoparticles is size, and they generally vary from $10-1000 \mathrm{~nm}$, prepared from several biomaterials. When used in vivo, the size of polymeric nanoparticles can also prevent immune recognition of the loaded protein, thus overcoming a major difficulty of in vivo protein stability [11] [12].

Poor bioavailability, inadequate stability and shelf life, immunogenicity, short plasma half-life, and poor penetration across biological membranes are issues of polymeric protein carriers that have been demonstrated in vivo. To develop ideal therapeutic polymeric nanoparticles, several key features including enhanced drug solubility, controlled release of molecules, prevention of initial bursting, avoidance of undesirable side effects, improved drug distribution, and targeting of diseased tissue must be considered for practical applications [13].

This review presents an overview of the current state of polymeric nanoparticles. First, polymer types, fabrication methods, and characterization of polymeric nanoparticles are discussed (Figure 1). The following section focuses on current polymeric nanoparticles for protein delivery. The final section focuses on the advantages and limitations of polymeric nanoparticles.

\section{Nanoparticle Polymers}

For clinical success using polymeric nanoparticles, several studies have focused on polymer selection for polymeric nanoparticles. Numerous natural and synthetic polymers are currently in use and have been adapted for clinical and preclinical applications of polymeric nanoparticles.

Several factors are important in choosing an appropriate polymer for the preparation of polymeric nanoparticles, such as biocompatibility, safety, and immunogenicity (i.e., they should not cause inflammatory or foreign-body reactions) [4]-[7]. The polymer must also be suitable for manufacturing techniques that generate nanoparticles, and ideal polymeric nanoparticles have adjustable morphological and biodegradation properties under in vivo circulation. Degradation properties, which are dependent on attributes such as polymer molecular weight, size, and microstructure of polymeric nanoparticles, are also important, with degradation time and the formation of nontoxic breakdown products of particular importance.

Polymers with biodegradable properties are mainly used as polymeric nanoparticles. Natural polymers, such as chitosan, gelatin, sodium alginate, and albumin are chiefly used, though synthetic polymers such as poly (ethylene glycol) (PEG), polylactides (PLA), polyglycolides (PGA), poly(lactide-co-glycolides) (PLGA), polycaprolactone (PCL), poly(hydroxy butyrate) (PHB), poly(2-hydroxy ethyl methacrylate) (PHEMA), poly ( $N$ (2-hydroxypropyl) methacrylamide) (PHPMA), poly(methyl methacrylate) (PMMA), and poly(vinyl alcohol) (PVA) are also utilized as biodegradable polymers as shown in Figure 2 [4]-[7] [14]-[18]. These polymers can

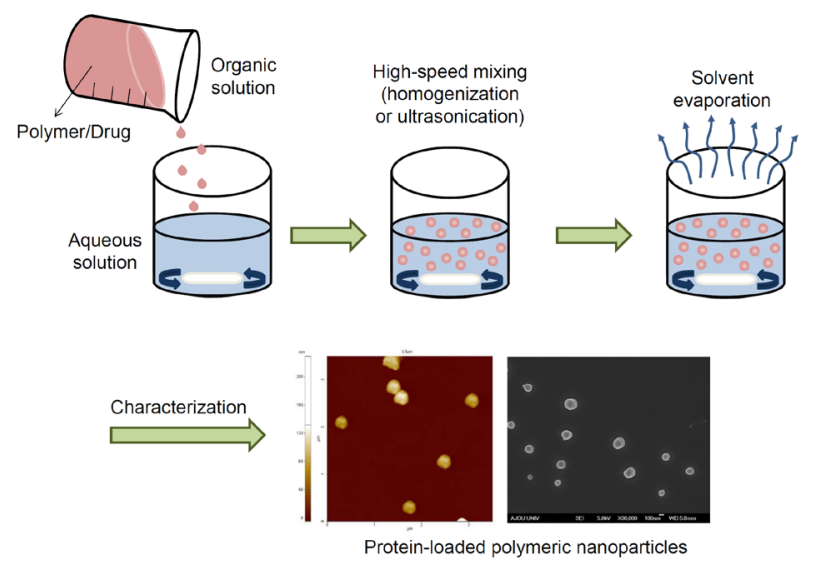

Figure 1. Schematic image for preparation of protein-loaded polymeric nanoparticles. 


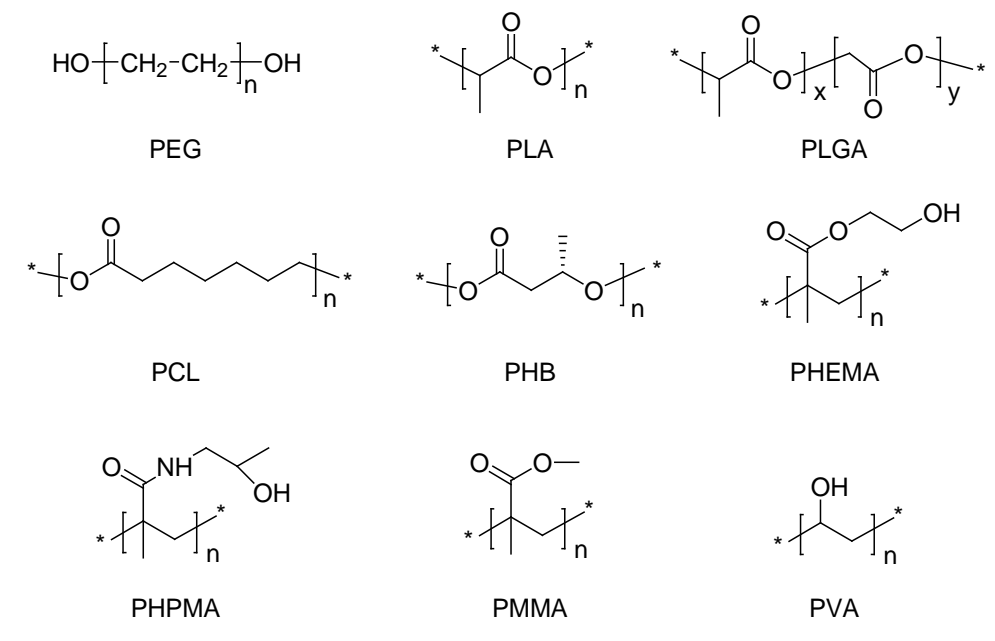

Figure 2. Typical polymers for polymeric nanoparticles.

be used in controlled delivery formulations as they are non-toxic and free of harmful and leachable impurities. Thus, the above polymers have great potential as carrier materials for pharmaceutical and biomedical applications. In the following section, albumin, gelatin, chitosan, PLGA, and PEG are discussed in the context of nanoparticle preparation.

\subsection{Albumin}

Albumin is a member of a globular protein family and is biodegradable, water-soluble, moderately soluble in concentrated salt solutions, and denatured by heat. Due to high binding of various drugs, the albumin matrix can be used for effective incorporation of drugs. Albumin can be used in the following drug delivery technologies: coupling of low-molecular weight drugs to exogenous or endogenous albumin, conjugation with bioactive proteins, and encapsulation of drugs into albumin-based nanoparticles [19]. The preparation of albumin-based nanoparticles is generally by desolvation, and prepared albumin-based nanoparticles have been evaluated both on particle size and on the quantity of protein dissolved in the aqueous phase after desolvation correlated with the amount of ethanol added as the desolvating agent [20]. Albumin-based nanoparticles can compete with drug interactions for albumin binding sites, therefore affecting potency.

\subsection{Gelatin}

Gelatin, which is derived from collagen obtained from various animal sources, is a translucent and colorless solid material commonly used in biomedical applications and also used in the preparation of nanoparticles. Gelatin-based nanoparticles are formed by a desolvation process, with the remaining sediment and supernatant analyzed for molecular weight distribution after the initial desolvation step [21]. Gelatin-based nanoparticles can easily be surface-modified by the introduction of several functional groups, which can be used for the additional attachment of functional proteins [22]. Strict regulations apply in the manufacturing of gelatin-based nanoparticles, as gelatin is produced from natural raw materials, which originate from animals.

\subsection{Chitosan}

Chitosan is a linear polysaccharide composed of randomly distributed $\beta$-(1-4)-linked D-glucosamine (deacetylated unit) and N-acetyl-D-glucosamine (acetylated unit), made from crustacean shells treated with sodium hydroxide. Chitosan is one of the most useful polymers as a drug carrier due to its mucoadhesivity and ability to enhance penetration of large molecules across mucosal surfaces [23]. Chitosan possess positively charged amino groups and thus can interact with negatively charged counter ions [24]. Chitosan-based nanoparticles are produced by ionic gelation, resulting in nanoparticles that are $400 \mathrm{~nm}$ in diameter. The positive charge of chitosan-based nanoparticles affects solubility in neutral and basic environments, while in acidic environments, result in increased solubility. These characteristics allow the usage of chitosan to easily deliver a drug to an acidic environment, which is important in biomedical applications. 


\subsection{PLGA}

PLGA is a synthetic copolymer produced by random ring opening copolymerization of glycolide and lactide. The major advantage of PLGA is that it undergoes complete biodegradation in aqueous media, resulting in the two original monomers (lactic and glycolic acid), which can be metabolized and eliminated as carbon dioxide and water or excreted unchanged by the kidney [25]-[27]. It possesses not only extreme biocompatibility but also high mechanical strength, making it suitable for a large variety of medical artifices such as sutures or fibers. PLGA-based nanoparticles present high-grade recognition by the reticuloendothelial system of the liver and spleen that remove them from the circulation and reduce the residence time of nanoparticles in the bloodstream drastically, thus avoiding delivery of nanoparticles to selected organs or tumors. PLGA-based nanoparticles are prepared by solvent displacement techniques and/or salting-out techniques, and range in size from 150 - $240 \mathrm{~nm}$ [28] [29].

\subsection{PEG}

PEG is a non-ionic hydrophilic polyether synthesized by polymerization of the monomer ethylene glycol. PEG is commonly utilized in medicine in various capacities, including orally as a laxative, in drug formulations as an excipient, and in capsule preparations as a coating agent. PEG does not biodegrade in the body and thus is excreted unchanged in kidney. Although PEG is a non-biodegradable polymer, it is extremely biocompatible and does not accumulate in tissue, especially for a low molecular weight polymer [31].

\section{Preparation of Protein-Loaded Polymeric Nanoparticles}

To determine which technique to use for the preparation of nanoparticles, the nature of the drug, mode of administration, duration of drug stability, duration desired for delivery, and site for administration must all be considered, as various difficulties are encountered in formulating proteins for therapeutic usage.

Several methods have been developed for the preparation of nanoparticles [32] [33]. The typical methods for preparation of protein-loaded nanoparticles were shown in Figure 3. With regards to technological advantages and drawbacks, four techniques are discussed in the following section: emulsification/solvent evaporation, emulsification/solvent diffusion, solvent displacement, and salting-out.

\subsection{Emulsification/Solvent Evaporation}

Emulsification/solvent evaporation is based on two mechanisms: 1) emulsification of a polymer solution into an aqueous phase, and 2) evaporation of polymer solvent and polymer precipitation as nanoparticles. Micro- and nano-emulsions are frequently prepared in combination with isotropic, thermodynamically stable transparent (or translucent) systems of oil, water, and (co-) surfactant [34]-[36]. Using a mixture of protective excipients as the dispersed organic phase, more stable particles can be prepared under high pressure and temperature [37]. PLA,

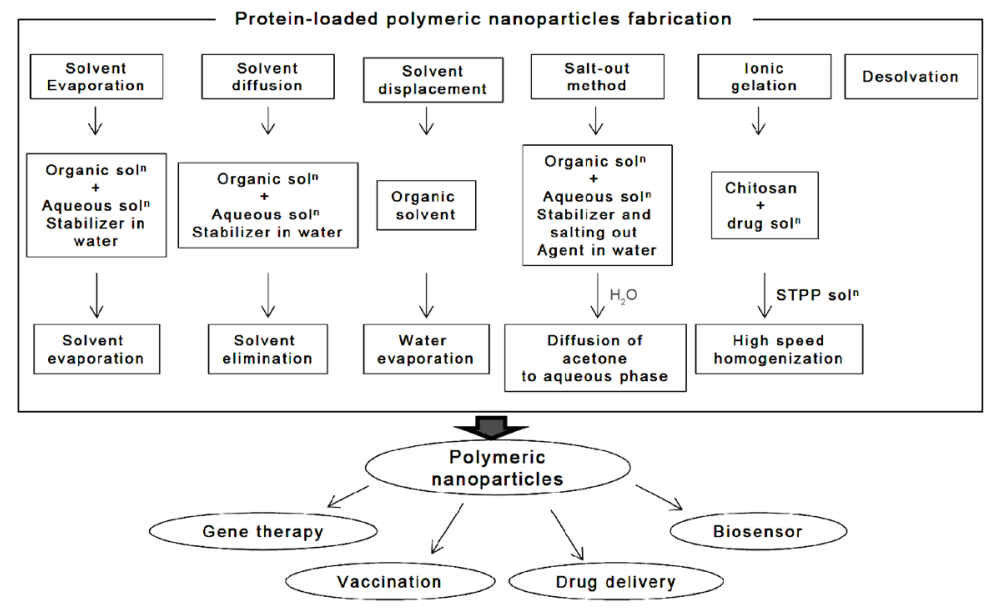

Figure 3. Preparation of protein-loaded polymeric nanoparticles. 
PLGA, PCL, PHB, albumin, gelatin, and chitosan are frequently used polymers. The effectiveness of solvent evaporation to produce nanoparticles is dependent on successful entrapment of protein within particles, and thus is most successful with protein drugs that are poorly soluble in the aqueous medium comprising the continuous phase.

\subsection{Emulsification/Solvent Diffusion}

The polymer is dissolved in an organic phase (e.g., benzyl alcohol, propylene carbonate, or ethyl acetate), which must be partially miscible in water. Diffusion of the organic solvent and the counter diffusion of water into the emulsion droplets induce the formation of polymeric nanoparticles [38]. Important parameters that affect nanoparticle size by emulsion diffusion include polymer concentration, solvent nature, surfactant weight, viscosity, phase ratio, stirring rate, solvent nature, temperature, and flow of water added. This method has high encapsulation efficiencies of up to $70 \%$. Several protein-loaded nanoparticles have been produced by emulsion/solvent diffusion.

\subsection{Solvent Displacement}

Solvent displacement is the continuous emulsification of an amphiphilic organic internal phase solution containing dissolved polymer into the aqueous external phase (surfactant) [39]. Nanoparticles are formed instantaneously by rapid solvent diffusion. Afterwards, solvent displacement forms nanoparticles when small amounts of non-toxic oil are incorporated in organic phase. This method is a convenient and rapid one-step manufacturing process for the preparation of monodispersed polymeric nanoparticles in a size range of approximately 5 $300 \mathrm{~nm}$.

\subsection{Salt-Out Method}

In the salt-out method, the polymer is dissolved in the organic phase, which should be water-miscible, such as acetone or tetrahydrofuran [40]. The aqueous phase contains the emulsifier and a high concentration of salts, which are not soluble in the organic phase. The rapid addition of water to the emulsion, under mild stirring, reduces the ionic strength and leads to migration of the water-soluble organic solvent to the aqueous phase, inducing the formation of polymeric nanoparticles. This process has an important role in protein encapsulation efficiency, and is advantageous in minimizing the stress of protein encapsulation.

\subsection{Ionic Gelation}

Polymeric nanoparticles are prepared using ionic hydrophilic polymers such as chitosan and gelatin. The method involves a mixture of two aqueous phases: 1) chitosan as the cationic ion and 2) poly anion sodium tripolyphosphate. Ionic gelation involves the transition of material from liquid to gel due to ionic interactions at room temperature. Factors such as $\mathrm{pH}$, concentration, component ratio, and mixing method affect the preparation of electrostatically formed nanoparticles [41]. This method produces nanosize particles of less than $500 \mathrm{~nm}$, depending on the type, molecular weight, and chitosan concentration.

\subsection{Desolvation}

Desolvation is a thermodynamically driven self-assembly process for polymeric materials, which prepares nanoparticles of a controlled size [42]. The obtained nano-capsules are vesicular, where the drug is essentially encapsulated in the central core and surrounded by a polymeric sheath. Polymeric nanoparticles form particles of different sizes depending on preparation conditions such as protein content, $\mathrm{pH}$, ionic strength, cross-linking agent concentration, agitation speed, and amount of desolvating agent.

\section{Characterization of Protein-Loaded Polymeric Nanoparticles}

Characterization and morphological analysis of nanoparticles is performed using tools such as transmission electron microscopy (TEM), scanning electron microscope (SEM), atomic force microscopy (AFM), dynamic light scattering (DLS), X-ray photoelectron spectroscopy (XPS), powder X-ray diffraction (XRD), ultravioletvisible spectroscopy, dual polarization interferometry, nuclear magnetic resonance (NMR), and nanoparticle 
tracking analysis (NTA) [43] [44].

The appropriate characterization of the protein-loaded polymeric nanoparticles requires several analytical methods. There are many characterizations of the protein-loaded polymeric nanoparticles to be assessed because of the stability of protein-loaded polymeric nanoparticles and release kinetics of incorporated protein from protein-loaded polymeric nanoparticles. Surface area and porosity, solubility, particle size distribution, aggregation, hydrated surface analysis, zeta potential, wettability, adsorption potential, and shape and size of the interactive surface should be considered for formation of protein-loaded polymeric nanoparticles. However it is always a challenge for the researchers to characterize protein-loaded polymeric nanoparticles due to more particularly its small particle size. Therefore, intensive research needs to be done to characterize protein-loaded polymeric nanoparticles on themolecular level.

\section{Conclusion and Future Prospects}

The importance of protein drugs is growing, and studies have improved the understanding of various proteins and their roles in human health and disease [45]-[49]. However, limitations of protein structure sensitivity to environmental conditions, the necessity to overcome problems associated with protein degradation, to provide sustained protein delivery, and to enhance therapeutic efficacy have led to the consideration of specific administration strategies.

There have been significant advances in protein-loaded nanoparticles in (pre-)clinical studies over the past 20 years. Protein-loaded nanoparticles can provide prolonged protein drug release after in vivo implantation. Protein-loaded polymeric nanoparticles protect proteins from degradation and increase their stability, and allow controlled release for a sustained period of time. When injected, protein released from protein-loaded polymeric nanoparticles can be well-tolerated in animal models and in humans. Thus, the use of protein-loaded nanoparticles may decrease the frequency of required injections by increasing protein drug stability.

A significant challenge for the clinical success of protein-loaded polymeric nanoparticles is the necessity to maintain therapeutically acceptable levels and to develop ideal zero-order release kinetics profiles over longer periods of time in vivo, allowing for extended use in chronically ill patients.

Future studies will focus on commercializing protein-loaded polymeric nanoparticles for sustained protein drug release in humans, which will ultimately require substantial and continual collaborative research among material, pharmaceutical, and clinical scientists.

\section{References}

[1] Murriel, C.L. and Dowdy, S.F. (2006) Influence of Protein Transduction Domains on Intracellular Delivery of Macromolecules. Expert Opinion on Drug Delivery, 3, 739-746. http://dx.doi.org/10.1517/17425247.3.6.739

[2] Salmaso, S. and Caliceti, P. (2013) Self Assembling Nanocomposites for Protein Delivery: Supramolecular Interactions of Soluble Polymers with Protein Drugs. International Journal of Pharmaceutics, 440, 111-123. http://dx.doi.org/10.1016/j.ijpharm.2011.12.029

[3] Hans, M.L. and Lowman, A.M. (2002) Biodegradable Nanoparticles for Drug Delivery and Targeting. Current Opinion in Solid State and Materials Science, 6, 319-327. http://dx.doi.org/10.1016/S1359-0286(02)00117-1

[4] Sinha, V.R. and Trehan, A. (2003) Biodegradable Microspheres for Protein Delivery. Journal of Controlled Release, 90, 261-280. http://dx.doi.org/10.1016/S0168-3659(03)00194-9

[5] Moghimi, S.M. and Szebeni, J. (2003) Stealth Liposomes and Long Circulating Nanoparticles: Critical Issues in Pharmacokinetics, Opsonization and Protein-Binding Properties. Progress in Lipid Research, 42, 463-478. http://dx.doi.org/10.1016/S0163-7827(03)00033-X

[6] Miller, T., Hill, A., Uezguen, S., Weigandt, M. and Goepferich, A. (2012) Analysis of Immediate Stress Mechanisms upon Injection of Polymeric Micelles and Related Colloidal Drug Carriers: Implications on Drug Targeting. Biomacromolecules, 13, 1707-1718. http://dx.doi.org/10.1021/bm3002045

[7] Tamilvanan, S. (2009) Formulation of Multifunctional Oil-in-Water Nanosized Emulsions for Active and Passive Targeting of Drugs to Otherwise Inaccessible Internal Organs of the Human Body. International Journal of Pharmaceutics, 381, 62-76. http://dx.doi.org/10.1016/j.ijpharm.2009.08.001

[8] Dombu, C.Y. and Betbeder, D. (2013) Airway Delivery of Peptides and Proteins Using Nanoparticles. Biomaterials, 34, 516-525. http://dx.doi.org/10.1016/j.biomaterials.2012.08.070

[9] Date, A.A. and Destache, C.J. (2013) A Review of Nanotechnological Approaches for the Prophylaxis of HIV/AIDS. Biomaterials, 34, 6202-6228. http://dx.doi.org/10.1016/j.biomaterials.2013.05.012 
[10] Chaudhary, S.H., Arora, V., Kholi, K., Kholi, K. and Kumar, V. (2013) Effect of Physicochemical Properties of Biodegradable Polymers on Nano Drug Delivery. Polymer Reviews, 53, 546-567. http://dx.doi.org/10.1080/15583724.2013.828751

[11] Vrignaud, S., Benoit, J.P. and Saulnier, P. (2011) Strategies for the Nanoencapsulation of Hydrophilic Molecules in Polymer-Based Nanoparticles. Biomaterials, 32, 8593-8604. http://dx.doi.org/10.1016/j.biomaterials.2011.07.057

[12] Kessler, M.R. (2012) Polymer Matrix Composites: A Perspective for a Special Issue of Polymer Reviews. Polymer Reviews, 52, 229-233. http://dx.doi.org/10.1080/15583724.2012.708004

[13] Rao, J.P. and Geckeler, K.E. (2011) Polymer Nanoparticles: Preparation Techniques and Size-Control Parameters. Progress in Polymer Science, 36, 887-913. http://dx.doi.org/10.1016/j.progpolymsci.2011.01.001

[14] Jenning, V., Gysler, A., Korting, M.S. and Ghola, S.H. (2000) Vitamin A Loaded Solid Lipid Nanoparticles for Topical Use: Occlusive Properties and Drug Targeting to the Upper Skin. European Journal of Pharmaceutics and Biopharmaceutics, 49, 211-218. http://dx.doi.org/10.1016/S0939-6411(99)00075-2

[15] Yun, Y.-P., Lee, S.-Y., Kim, H.-J., Song, J.-J. and Kim, S.E. (2013) Improvement of Osteoblast Functions by Sustained Release of Bone Morphogenetic Protein-2 (BMP-2) from Heparin-Coated Chitosan Scaffold. Tissue Engineering and Regenerative Medicine, 10, 183-191. http://dx.doi.org/10.1007/s13770-013-0389-1

[16] Kim, M.S., Kim, J.H., Min, B.H., Han, D.K. and Lee, H.B. (2011) Polymeric Scaffolds for Regenerative Medicine. Polymer Reviews, 51, 23-52. http://dx.doi.org/10.1080/15583724.2010.537800

[17] Haider Abdi, S.I., Choi, J.Y., Lee, J.S., Lim, H.J., Lee, C., Kim, J., Chung, H.Y. and Lim, J.O. (2012) In Vivo Study of a Blended Hydrogel Composed of Pluronic F-127-Alginate-Hyaluronic Acid for its Cell Injection Application. Tissue Engineering and Regenerative Medicine, 9, 1-9. http://dx.doi.org/10.1007/s13770-012-0001-0

[18] Kim, J.M., Han, T.S., Kim, M.H., Oh, D.S., Kang, S.S., Kim, G., Kwon, T.-Y., Kim, K.-H., Lee, K.B., Son, J.S. and Choi, S.H. (2012) Osteogenic Evaluation of Calcium Phosphate Scaffold with Drug-Loaded Poly(Lactic-co-Glycolic Acid) Microspheres in Beagle Dogs. Tissue Engineering and Regenerative Medicine, 9, 175-183. http://dx.doi.org/10.1007/s13770-012-0175-5

[19] Taheri, A., Dinarvand, R., Atyabi, F., Ahadi, F., Nouri, F.S., Ghahremani, M.H., Ostad, S.N., Borougeni, A.T. and Mansoori, P. (2011) Enhanced Anti-Tumoral Activity of Methotrexate-Human Serum Albumin Conjugated Nanoparticles by Targeting with Luteinizing Hormone-Releasing Hormone (LHRH) Peptide. International Journal of Molecular Sciences, 12, 4591-4608. http://dx.doi.org/10.3390/ijms12074591

[20] Wacker, M. (2013) Nanocarriers for Intravenous Injection-The Long Hard Road to the Market. International Journal of Pharmaceutics, 457, 50-62. http://dx.doi.org/10.1016/j.ijpharm.2013.08.079

[21] Munarin, F., Tanzi, M.C. and Petrini, P. (2012) Advances in Biomedical Applications of Pectin Gels. International Journal of Biological Macromolecules, 51, 681-689. http://dx.doi.org/10.1016/j.ijbiomac.2012.07.002

[22] Kang, A.R., Park, J.S., Ju, J., Jeong, G.S. and Lee, S.-H. (2014) Cell Encapsulation via Microtechnologies. Biomaterials, 35, 2651-2663. http://dx.doi.org/10.1016/j.biomaterials.2013.12.073

[23] Yun, Y.-P., Kim, S.E., Kang, E.Y., Kim, H.-J., Park, K. and Song, H.-R. (2013) The Effect of Bone Morphogenic Protein-2 (BMP-2)-Immobilizing Heparinized-Chitosan Scaffolds for Enhanced Osteoblast Activity. Tissue Engineering and Regenerative Medicine, 10, 122-130. http://dx.doi.org/10.1007/s13770-013-0386-4

[24] Bajpai, A.K., Bajpai, J., Saini, R. and Gupta, R. (2011) Responsive Polymers in Biology and Technology. Polymer Reviews, 51, 53-97. http://dx.doi.org/10.1080/15583724.2010.537798

[25] Yun, S.H., Kim, C.J., Kwon, O.K., Kim, W.I. and Kwon, O.H. (2012) Fabrication and Characterization of Biodegradable Nanofiber Containing Insulin. Tissue Engineering and Regenerative Medicine, 9, 33-39.

[26] Kim, J.I., Kim, D.Y., Kwon, D.Y., Kang, H.J., Kim, J.H., Min, B.H. and Kim, M.S. (2012) An Injectable Biodegradable Temperature-Responsive Gel with an Adjustable Persistence Window. Biomaterials, 33, 2823-2834.

http://dx.doi.org/10.1016/j.biomaterials.2012.01.004

[27] Kang, K.N., Kim, D.Y., Yoon, SM., Lee, J.Y., Lee, B.N., Kwon, J.S., Seo, H.W., Lee, I.W., Shin, H.C., Kim, Y.M., Kim, H.S., Kim, J.H., Min, B.H., Lee, H.B. and Kim, M.S. (2012) Tissue Engineered Regeneration of Completely Transected Spinal Cord Using Human Mesenchymal Stem Cells. Biomaterials, 33, 4828-4835. http://dx.doi.org/10.1016/j.biomaterials.2012.03.043

[28] Lee, J.Y., Kim, D.Y., Kim, G.H., Kang, K.N., Min, B.H., Lee, B., Kim, J.H. and Kim, M.S. (2011) Enhanced Stability of Nano-Emulsified Paclitaxel. Journal of Biomedical Science and Engineering, 4, 352-356. http://dx.doi.org/10.4236/jbise.2011.45044

[29] Kim, G.H., Lee, J.Y., Kang, Y.M., Kang, K.N., Kim, E.S., Kim, D.Y., Kim, J.H. and Kim, M.S. (2011) Preparation and Characterization of Self Emulsified Docetaxel. Journal of Nanomaterials, 2011, Article ID: 860376.

[30] Lee, J.H., Lee, H.B. and Andrade, J.D. (1995) Blood Compatibility of Polyethylene Oxide Surfaces. Progress in Polymer Science, 20, 1043-1079. http://dx.doi.org/10.1016/0079-6700(95)00011-4 
[31] Kim, S., Jo, S., Shin, E., Kim, D. and Noh, I. (2012) Evaluations of Nerve Cell Compatibility of Self Cross-Linking Chitosan-Poly(Ethylene Oxide) Hydrogel. Tissue Engineering and Regenerative Medicine, 9, 84-91. http://dx.doi.org/10.1007/s13770-012-0034-4

[32] Kowalczuk, A., Trzcinska, R., Trzebicka, B., Müller, A.H.E., Dworak, A. and Tsvetanov, C.B. (2014) Loading of Polymer Nanocarriers: Factors, Mechanisms and Applications. Progress in Polymer Science, 39, 43-86. http://dx.doi.org/10.1016/j.progpolymsci.2013.10.004

[33] Kim, J.I., Lee, S.H., Kang, H.J, Kwon, D.Y., Kim, D.Y., Kang, W.S., Kim, J.H. and Kim, M.S. (2011) Examination of Phase Transition Behavior of Ion Group Functionalized MPEG-b-PCL Diblock Copolymers. Soft Matter, 7, 8650-8656. http://dx.doi.org/10.1039/c1sm05977g

[34] Ito, F., Kanakubo, Y. and Murakami, Y. (2011) Rapid Preparation of Monodisperse Biodegradable Polymer Nanospheres Using a Membrane Emulsification Technique under Low Gas Pressure. Journal of Polymer Research, 18, 2077 2085. http://dx.doi.org/10.1007/s10965-011-9617-3

[35] Szüts, A. and Szabó-Révész, P. (2012) Sucrose Esters as Natural Surfactants in Drug Delivery Systems-A Mini- Review. International Journal of Pharmaceutics, 433, 1-9. http://dx.doi.org/10.1016/j.ijpharm.2012.04.076

[36] Lee, S.Y., Hyun, H., Youn, J.Y., Kim, B.S., Song, I.B., Kim, M.S., Lee, B., Khang, G. and Lee, H.B. (2008) Preparation of Nano-Emulsified Paclitaxel Using MPEG-PLGA Diblock Copolymers. Colloids and Surfaces A: Physicochemcal and Engineering Aspects, 313-314, 126-130. http://dx.doi.org/10.1016/j.colsurfa.2007.04.157

[37] Tran, V.T., Benoît, J.P. and Venier-Julienne, M.C. (2011) Why and How to Prepare Biodegradable, Monodispersed, Polymeric Microparticles in the Field of Pharmacy? International Journal of Pharmaceutics, 407, 1-11. http://dx.doi.org/10.1016/j.ijpharm.2011.01.027

[38] Astete, C.E. and Sabliov, C.M. (2006) Synthesis and Characterization of PLGA Nanoparticles. Journal of Biomaterials Science-Polymer Edition, 17, 247-289. http://dx.doi.org/10.1163/156856206775997322

[39] Rodríguez-Abreu, C., Shrestha, R.G., Shrestha, L.K., Harush, E. and Regev, O. (2013) Worm-Like Soft Nanostructures in Nonionic Systems: Principles, Properties and Application as Templates. Journal of Nanoscience and Nanotechnology, 13, 4497-4520. http://dx.doi.org/10.1166/jnn.2013.7470

[40] Liu, G., Men, P., Perry, G. and Smith, M.A. (2009) Metal Chelators Coupled with Nanoparticles as Potential Therapeutic Agents for Alzheimer's Disease. Journal of Nanoneuroscience, 1, 42-55. http://dx.doi.org/10.1166/jns.2009.005

[41] Dutta, P.K., Ravikumar, M.N.V. and Dutta, J. (2002) Chitin and Chitosan for Versatile Applications. Journal of Macromolecular Science, Part C: Polymer Reviews, 42, 307-354. http://dx.doi.org/10.1081/MC-120006451

[42] Elzoghby, A.O., Samy, W.M. and Elgindy, N.A. (2012) Albumin-Based Nanoparticles as Potential Controlled Release Drug Delivery Systems. Journal of Controlled Release, 157, 168-182. http://dx.doi.org/10.1016/j.jconrel.2011.07.031

[43] Gagliardi, M., Bardi, G. and Bifone, A. (2012) Polymeric Nanocarriers for Controlled and Enhanced Delivery of Therapeutic Agents to the CNS. Therapeutic Delivery, 3, 875-887. http://dx.doi.org/10.4155/tde.12.55

[44] Kumar, G., Shafiq, N. and Malhotra, S. (2012) Drug-Loaded PLGA Nanoparticles for Oral Administration: Fundamental Issues and Challenges Ahead. Critical Reviews in Therapeutic Drug Carrier Systems, 29, 149-182. http://dx.doi.org/10.1615/CritRevTherDrugCarrierSyst.v29.i2.20

[45] Gonçalves, G., Vila, M., Portolés, M.T., Vallet-Regi, M., Gracio, J. and Marques, P.A. (2013) Nano-Graphene Oxide: A Potential Multifunctional Platform for Cancer Therapy. Advanced Healthcare Materials, 2, 1072-1090.

[46] Date, A.A. and Destache, C.J. (2013) A Review of Nanotechnological Approaches for the Prophylaxis of HIV/AIDS. Biomaterials, 34, 6202-6228. http://dx.doi.org/10.1016/j.biomaterials.2013.05.012

[47] Jayasuriya, A. and Darr, A. (2013) Controlled Release of Cisplatin and Cancer Cell Apoptosis with Cisplatin Encapsulated Poly(Lactic-co-Glycolic Acid) Nanoparticles. Journal of Biomedical Science and Engineering, 6, 586-592. http://dx.doi.org/10.4236/jbise.2013.65074

[48] Yamamoto, M., Takahashi, Y. and Tabata, Y. (2013) Controlled Release by Biodegradable Hydrogels Enhances the Ectopic Bone Formation of Bone Morphogenetic Protein. Biomaterials, 24, 4375-4383. http://dx.doi.org/10.1016/S0142-9612(03)00337-5

[49] Tanabe, K., Miura, T. and Yoshinari, M. (2013) Electrostatically Coupled State of Fluvastatin with Gelatin in Vitro. Journal of Hard Tissue Biology, 22, 451-454. http://dx.doi.org/10.2485/jhtb.22.451 
Scientific Research Publishing (SCIRP) is one of the largest Open Access journal publishers. It is currently publishing more than 200 open access, online, peer-reviewed journals covering a wide range of academic disciplines. SCIRP serves the worldwide academic communities and contributes to the progress and application of science with its publication.

Other selected journals from SCIRP are listed as below. Submit your manuscript to us via either submit@scirp.org or Online Submission Portal.
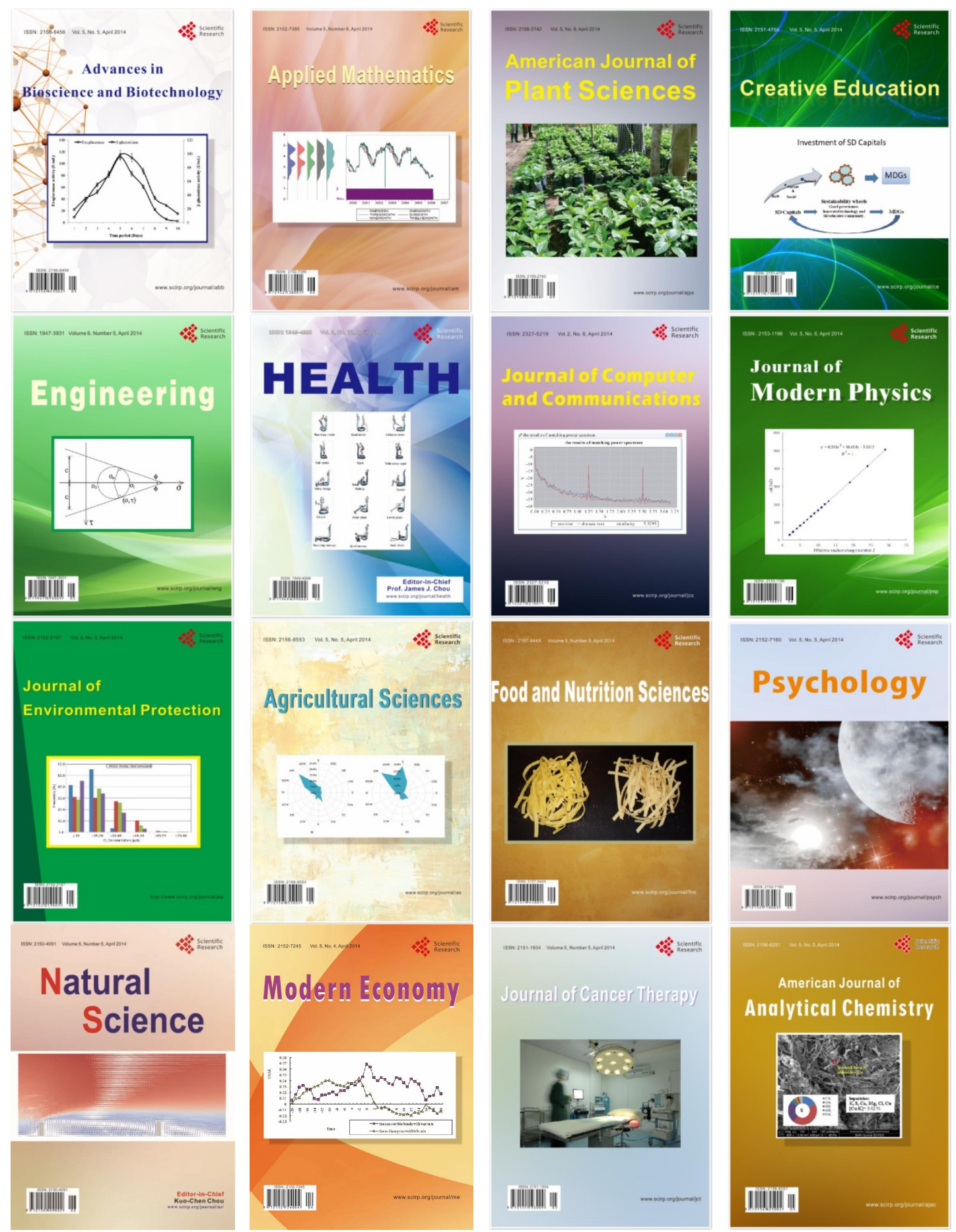